Revista Iberoamericana. Vol. LXVII, Núms. 194-195, Enero-Junio 2001, 201-217

\title{
EL DESENGAÑO DE LAS ALEGORÍAS Y LA ESCRITURA DE LA NACIÓN: EL CASO DE ANA LYDIA VEGA
}

\author{
POR \\ Miguel Gomes \\ The University of Connecticut-Storrs
}

\section{LitERATURA HISPANOAMERICANA Y ALEGORÍA}

El concepto de alegoría ha sido objeto de debates numerosos. Las disputas más complejas se inician con el romanticismo; si antes la categoría estaba confinada a un tipo de tropo (Lausberg 212-4) o de lectura (Murphy 238, 327; Curtius 292-5), la revisión a la que es sometida ampliará las perspectivas añadiendo una oposición al símbolo que supone la construcción de una cosmovisión en la que el último de estos dos términos representa la alternativa organicista romántica a la inmovilidad y rigidez clásicas. La suma posterior a esos tres ángulos del estricto entendimiento de la alegoría como modalidad genérica existente aunque tenue antes; formalizada por críticos de la segunda mitad del siglo xxcompleta las cuatro clases de fenómenos a los que la palabra “alegoría” puede aludir en las discusiones registradas hasta la fecha (Van Dyke 20 y ss.).

Un repaso panorámico de la historia de las argumentaciones en torno al concepto permite observar dos momentos claves: uno, alrededor de 1800; el otro, a partir de 1950. En el primero, figuras como Goethe (Maxims 1112-3) o Hegel (2:7 y 134) desdeñan lo alegórico por su incapacidad para lo ambiguo y misterioso, atributos del arte. En el segundo momento, luego de rescates esporádicos —C.S. Lewis; Empson (112 y ss.); Benjamin (159 y ss.) - se comprueba una progresiva revaloración: Northrop Frye, Angus Fletcher, Maureen Quilligan, Paul de Man, Umberto Eco (Semiotics 14 y ss.), Carolynn Van Dyke, Gordon Teskey, Sayre Greenfield y otros han dedicado páginas indispensables al problema. En general, la tónica ha sido desde Frye revertir los términos románticos, pues en la antes detestada "falsedad" de lo alegórico se hallan importantes indicios de que el uso del lenguaje supone la fabricación tropológica de concepciones tanto de lo literario como de lo real.

De Man es el crítico más característico de todos los que en la segunda mitad del siglo xx han hecho de la alegoría un instrumento para entender los dilemas de la representación en la cultura de Occidente. En diversos ensayos trata de desconstruir el pensamiento romántico precisamente atacando los ataques de Coleridge a la alegoría. De especial importancia es "The Rhetoric of Temporality", donde llega a la conclusión de que lo alegórico proclama abiertamente la artificiosidad lingüística de nuestras concepciones del universo (Blindness 207). Ese camino finalmente conduce, tras casi equivaler a una aporía en ciertos pasajes de Allegories of Reading (275), a su entronización como callejón sin salida 
donde el lenguaje se revela incapaz de ofrecernos verdades absolutas (Aesthetic Ideology 69). Por supuesto, los extremos de tal visión pronto serán denunciados. Una manera de hacerlo, la preferida por Teskey, es el recordatorio de que bajo la construcción alegórica nos espera un discurso de poder; toda alegoría evoca una escisión en la conciencia humana entre la vida y el misterio, lo real y lo ideal, entre una narración y su moraleja “que se repara, o al menos se oculta, imaginando una jerarquización donde ascendemos a la verdad” (2). En la línea de pensamiento de Teskey, Greenfield ha ido más lejos al denunciar en la alegoría y la allegoresis modernas, a veces, una postura acomodaticia, a veces, una sed de dominio, ambas disfrazadas de sabiduría (132 y ss.).

La posibilidad de ampliar este cuadro teórico son numerosas; con el "proteísmo” del concepto que estudiamos parece competir el del parecer de quienes lo interpretan. Sin ánimo de ignorar discusiones de valor indudable, me atendré en estas páginas, por razones de economía, a una definición provisional que juzgo suficiente para nuestro propósito estudiar ciertos fenómenos de la narrativa hispanoamericana. Entenderé aquí por “alegórico” todo relato cuyos referentes sean claramente situables en otros relatos, es decir, en fenómenos no perceptibles sino a través de experiencias lingüísticas, aunque no necesariamente verbales. Lo que equivale a describir la alegoría como discurso literario, pictórico, arquitectónico o de cualquier tipo que remita de manera no velada a discursos que a su vez se convierten en ausencias continuamente presentes, que antedatan a la alegoría y están revestidas de una dignidad mayor que ella, simple intermediaria de una "verdad" que corona en su conjunto al cosmos.

Meditar acerca de este campo es imprescindible si deseamos percibir los avatares de las letras hispanoamericanas en los umbrales del nuevo milenio. En un artículo célebre de 1986, Fredric Jameson dictaminó que todas las literaturas de las periferias del capitalismo están entregadas a la creación exclusiva de un tipo específico de "alegoría”:

[...] los textos del Tercer Mundo, hasta cuando aparentan ser privados y estar investidos por una apropiada dinámica libidinal, necesariamente proyectan una dimensión política configurada como alegoría nacional: la historia del destino individual privado es siempre una alegoría de la conflictiva situación de la cultura y la sociedad públicas. (69)

Críticos eficientes, algunos, como Aijaz Ahmad, oriundos de las zonas a las que Jameson se refiere, ya han moderado un planteamiento tan rotundo que, además de estereotipador y prescriptivo, rompe las barreras de la historia — “siempre”-, acusación grave si se dirige a un marxista. Pero igualmente podrían destacarse fallas más formales en la proposición: el uso de la palabra “alegoría” en un sentido enormemente vago, en el que no se sabe si se piensa en un género, en un patrón estructural capaz de aparecer en cualquier narración o en la allegoresis, o sea, una lectura engendradora de alegorías, tal como la conceptúa Quilligan (26). Esto último se hace patente cuando nos enfrentamos a los párrafos donde Jameson trata de validar su rescate de la alegoría rechazando cualidades negativas que los románticos habían adherido a ella:

Nuestro concepto tradicional de la alegoría [...] es el de un grupo de figuras y personificaciones contrastables con una tabla de equivalencias exactas; esa es sólo una visión unidimensional de este proceso de significación, que se agilizaría si estuviéramos 
dispuestos a aceptar la noción más alarmante de que tales equivalencias están en constante cambio y transformación en cada presente perpetuo del texto. (73)

Como bien lo enfatiza Teskey, Jameson en pasajes similares a ése confunde "la interpretación alegórica con la composición de alegorías, subsumiendo una preocupación generalizada sobre la heterogeneidad en el espacioso marbete de 'lo alegórico”” (2). La siguiente reflexión de Teskey es no menos pertinente: "alegorizar un texto — decir que dice algo distinto de lo que dice - no lo convierte en una alegoría” (2); para leerlo apropiadamente como alegórico éste debe “contener instrucciones para su propia interpretación” (3).

En lo que respecta a estos renglones, preferiría que considerásemos la sugerencia hecha en 1986 por Jameson no como verdad o falacia filológica, sino como aportación que, pese a sus inexactitudes, señala áreas críticas para una cabal comprensión de la cultura hispanoamericana. Una ojeada a la tradición moderna de su literatura, la que empieza con la Independencia, permite distinguir una larga serie de obras que si bien no son alegorías en el sentido de The Pilgrim's Progress o The Faerie Queene, sí presentan elementos atribuibles a una "modulación” transgenérica de lo alegórico (Fowler 192). Lo alegórico, así entendido, se encuentra en ellas de la misma manera como lo "satírico" o "pastoral" figuran en escritos genealógicamente diversos: novelas, poemas, obras teatrales. Carolynn Van Dyke ha propuesto un nombre adecuado para ese tipo de prolongación histórica, supervivencia como vestigio — sin embargo activo- de la antigua alegoría literal: "postalegoría” (290 y ss.). Los elementos post-alegóricos en los textos hispanoamericanos a los que me refiero, aunque no agotan la totalidad del discurso, han sido constatados por su público como vitales. De limitarnos, por la desmesura del corpus, a una sola manifestación literaria, la narrativa, pronto daríamos con un canon que no sólo contiene vestigios de alegorías, sino en el que estos, en efecto, tal como lo aseveraba Jameson, se mueven en las agitadas aguas de proyectos nacionales deseados, satirizados o desmitificados: Periquillo Sarniento, El matadero, Martín Rivas, Aves sin nido, Doña Bárbara, Hombres de maíz, Pedro Páramo, Rayuela, Cien años de soledad, Terra nostra, La guerra del fin del mundo... Ninguno de ellos, contengan o no "instrucciones", como sugiere Teskey, ha escapado de la allegoresis. Y en la mayor parte de los casos las lecturas han sido convincentes. Incluso en idilios como María, entre muchos otros del siglo xix, donde los planteamientos políticos no parecen centrales, se ha identificado con argumentos sólidos un "matrimonio de la alegoría histórica y el sentimentalismo” (Sommer 84). La lista de obras que modulan hacia terrenos alegóricos, desde luego, es muy extensa. No está de más explicar ese fenómeno como aspecto de un rasgo frecuentemente señalado en las letras hispanoamericanas: su predominante orientación transitiva. El escritor como protagonista del destino de su sociedad e intérprete de él. En esta coyuntura conviene recordar las advertencias de Teskey y Greenfield con respecto a los autores de alegorías: el sujeto que define su función en el seno de una comunidad como la de "cofundador" o "maestro" reclama sin duda una cuota de poder que lo eleva sobre el promedio de sus coterráneos. La profusión de “alegorías nacionales” en la narrativa posterior a la Independencia suele acompañar sutiles campañas personalistas. El discurso ausente que suscitan acaba incluso convirtiendo al autor en personaje de una narración que Gérard Genette llamaría “paratextual”: sería imposible no ver en Fernández de Lizardi al buen maestro que su Periquillo, el pueblo de México, lamentablemente nunca 
tuvo; en Echeverría, al sacrificado y admirable opositor unitario del “bárbaro” Rosas, dueño del matadero que es la Argentina; en Gallegos, al Santos Luzardo con iniciativas electorales; en Vargas Llosa, una solución política neoliberal para los fanáticos y enloquecidos místicos de Canudos que perduran en los actuales izquierdistas o derechistas extremos. A pesar de que la literatura moderna hispanoamericana está a punto de cumplir doscientos años y de que su ansiada transitividad ha tenido a lo sumo resultados fantasmales, sigue fiel a sus modelos y tics primigenios.

Describo una situación; no la condeno. En el nuevo siglo que se avecina para nuestras letras ¿hay perspectivas de un cambio de rumbo radical? La repetición discreta de ciertas posturas durante los últimos años permite sospechar reformas de las viejas costumbres. La subversión o crítica del modelo alegórico que conduce "en ascenso a la verdad" ya ha empezado, principalmente, con Borges (Álvarez 140-4), quien exploró la imposibilidad de deslindar la realidad, incluso la nacional, de su materia lingüística; por ese sendero se han adentrado varios escritores recientes: Ana Lydia Vega, César Aira, Sergio Chejfec, Ana Teresa Torres, Alejandro Rossi. Por cuestiones de espacio, me limitaré a profundizar en el caso de Vega, que considero especialmente ilustrativo.

\section{CONTRA LA RESPONSABILIDAD REPRESIVA}

Ana Lydia Vega no sólo ha intentado en algunos de sus cuentos ir más allá del alegorismo nacionalista usual, sino que en sus ensayos podemos percibir un esfuerzo por sustentar teóricamente tales inclinaciones. "Sálvese quien pueda: la censura tiene auto”, pieza incluida en Esperando a Loló (1994), asevera que una de las trampas en las que han caído casi todos sus compatriotas ha sido la de complacer una tradición intelectual "mesiánica" en la que el escritor tiende a convertirse, incluso a pesar suyo, en "la contrafigura moral del político” (84) que ha conducido a Puerto Rico al callejón sin salida o, mejor dicho, "el gran pozo-muro nacional de la Crisis de Identidad" (83). La "aureola épica de monje guerrero” (84) — en esto estaría lo más grave, a su modo de ver — supone un proyecto que exige "una ausencia total de contradicciones, una perfecta síntesis de virtudes, algo así como una vida ejemplar” (84).

En una lista burlesca, Vega resume las reglas de juego de quienes aspiren al lugar común: “escoger temas serios y profundos”; evitar todo humorismo que roce siquiera el territorio de los "Valores Nacionales"; mostrar solamente el "perfil más favorable posible de nuestro Pueblo-en-lucha” (85); buscar los "desenlaces optimistas”; y, en particular, mantener un "tono digno y solemne” (85). Por supuesto, quienes no sigan esos patrones podrán esperar las represalias, no de un comité oficial, sino de la conciencia propia, formada en dichos dogmas. Lo que Vega llama “autocensura” parece exigirle a todo escritor “la Gran Metáfora Definitiva que resuma, contenga y exorcice el Supertranque Colonial” (86). Aunque su vocabulario sea vacilante y en él se confundan "metáfora”, "arquetipo", "símbolo” y "alegoría”, el siguiente pasaje basta para comprobar que a lo que se refiere y lo que lamenta la escritora es exactamente aquello que había fascinado a Jameson en la literatura del "Tercer Mundo": 
[...] el catálogo nacional de los mitos de orígenes sigue enriqueciéndose con imaginativos símbolos totalizantes de la vieja y siempre nueva realidad colonial. Pienso, por ejemplo, en el arquetípico tapón de La guaracha del Macho Camacho, en los alegóricos entierros de Rodríguez Juliá, en la metafórica casa familiar de Magali García Ramis y de toda la narrativa de los setenta... y tantos otros símbolos parafraseantes que han seguido creando a lo sucu-sumuco nuestras prolíficas musas mientras nos ufanamos de haber roto triunfalmente la Gran Cadena Ancestral. (87)

Lo criticado por Vega, con todo, no es el artificio en sí — después de todo, obras maestras de la narrativa continental como Cien años de soledad incurren en él—, sino, más bien, lo reiterativo de su aparición, que deja entrever un “endémico volvernos hacia nosotros mismos para mordernos la cola” (87). Nótese que en las citas previas ya encontramos una subversión inmediata de las reglas del buen mesianismo literario: desparpajo, ironías acerca de autores canónicos — por tanto, ya tempranos "Valores Nacionales”-, ausencia de solemnidad. Lo que sigue es la debida contradicción de quien no aspira al sitial de monja guerrera:

Y créanme que si me permito tirar este peñón es porque mi apartamento también tiene sunroof. Archivadas en mis bolsillos llevo par de metaforillas de las mentadas. ¿Se acuerdan del barquito de Encancaranublado? (87)

Desde luego, la obra de Vega ha oscilado entre lo que ella denuncia y los ideales que “Sálvese quien pueda” esboza. Acaso Encancaranublado (1982) en su totalidad contiene los momentos menos originales de su carrera, en los que la prédica, demasiado obvia, apenas se disfraza de provocación gracias a los malabarismos siempre entretenidos de su coloquialismo isleño. En el cuento que da título al libro, dedicado "A la confederación caribeña del futuro para que llueva pronto y escampe” (7) — dedicatoria ya alegórica y fácilmente interpretable - un haitiano balsero recoge en alta mar a un cubano y a un dominicano, todos rumbo a los Estados Unidos. Después de una tensa convivencia, las riñas acaban ocasionando un naufragio del que sólo los salva un barco norteamericano; confinados a la bodega, los “niggers" son puestos bajo la tutoría de un "spik” puertorriqueño, cuya apariencia poco triunfal les da ya una idea de lo que será su futuro. De hecho, el barco que los ha recogido tiene todo el aire de una nave de esclavos. "Puerto Rican Syndrome”, pese al tono carnavalesco que acompaña a las acciones multitudinarias, no deja de estar rígidamente reglamentado por el alegorismo, incluso didáctico y perceptible desde el epígrafe mismo, tomado de Salas Quiroga: "Puerto Rico es el cadáver de una sociedad que no ha nacido” (39). Un par de niños, puertorriqueños y consumistas, que religiosamente miran televisión, un día son testigos de una aparición: "una señora linda, rubia, de ojos azules, vestida de rojo, azul y blanco y con el velo llenito de estrellas” (41). El milagro pronto se extiende y hay tumultos de isleños ansiosos de ver también a la Madona, así envuelta en la bandera estadounidense y causa de paroxismos que culminan en cataclismo. Como Captain-Hidalgo ha sugerido, “'Puerto Rican Syndrome’ no es nada más que [sic] una alegoría de lo que ha ocurrido desde la llegada de los norteamericanos a la isla” (307). La "Historia del arroz con habichuelas"da asimismo una idea adecuada de la totalidad de la colección: en una fonda, el arroz blanco y las habichuelas de color tienen diferencias que 
rayan en la antipatía; cuando los visita un forastero — el hot dog —, los clientes se abalanzan sobre él y olvidan el plato tradicional, que únicamente volverá a tener éxito cuando el arroz y las habichuelas "llegan a un consenso sin plebiscito" (140) y se unen "en criollo casorio. En mestizo mejunge [...]. En puertorriqueñísimo pacto para la victoria” (139).

Algunas de las neotradiciones — a la Ricardo Palma— que figuran en Falsas crónicas del sur (1991) recaen igualmente en la "Gran Metáfora Definitiva”, aunque sin la rimbombancia frecuente en Encancaranublado. "El regreso del héroe”, por ejemplo, relata el retorno a la Isla, en 1895, de un líder pardo, desterrado por haber conspirado contra las autoridades españolas. El motivo de que se lo perdone es un cambio de gobierno en España, próximo a "la tan cacareada autonomía” (125) lograda por Muñoz Rivera para Puerto Rico. Una multitud se ha congregado para saludar al conspirador pero, víctima de un infarto, la única manera de que éste responda a las masas es con la ayuda de un pícaro voyeur que, para burlar a las autoridades, se ha ocultado en el coche y no desea que por ningún motivo se detenga: el truhán coge la mano del cadáver, la saca por la ventanilla y la agita. El ademán del héroe calma la "sed de epopeya de su gente” (133). Tal modulación a lo alegórico sólo acepta una duda menor: decidir si los substitutos de independencia —autonomismos de cualquier tipo — o si el usual engrandecimiento del pasado patrio — pesa no haber cuajado en el presente en un Estado- es el falso héroe, el cadáver que saluda. No menos claro es “Cupido y Clío en el Bazar Otero” donde entre un grupo de conspiradores decimonónicos contra el gobierno colonial hay una "mujer fascinante” cuyo nombre jamás será revelado al personaje que se enamora de ella — ”una heroína de la patria” es toda la información que obtiene (161). Antes del desenlace, sin embargo, sabemos que el disfraz que ha adoptado la prófuga de la ley es el de mujer embarazada: si, por una parte, los esfuerzos de la mujer en la lucha por la independencia puertorriqueña no han sido reconocidos — permanecen anónimos_- por otra, el nacimiento de la nación no ha sido, hasta ahora, real, sino una farsa de carnaval.

A pesar de que incursiones como las anteriores basten para explicar por qué Vega se ha convertido en una de las escritoras más representativas del ámbito cultural puertorriqueño, pues sin duda ha colmado las expectativas del sector del público que espera la clave "mesiánica”, acaso lo más memorable de su obra sean, a la larga, aquellos escritos donde se rebela contra el modelo ourobórico por ella misma condenado. De hecho, varios de sus relatos, más que complacer al lector, parecen haberse propuesto desconcertarlo y desafiar las fosilizaciones ideológicas del cliché, sea bienintencionado o no, sea patriótico, feminista o puramente estético. Sus mejores narraciones se insertan en un modelo paradójico, en el cual los textos se conciben como campos problemáticos que incitan al lector a participar activamente en la búsqueda de soluciones que, sin embargo, no acabarán paternalista o maternalistamente refrendadas por prédicas autoriales.

La mayoría de los cuentos incluidos en Vírgenes y mártires (1981) y la totalidad de Pasión de historia y otras historias de pasión (1987) ilustran esa vertiente de su trabajo. Los del primer volumen se han convertido ya en tempranos clásicos de las letras puertorriqueñas y han gozado de suficiente atención crítica. Si bien ésta a veces no da en el blanco, en más de un caso los resultados son satisfactorios a la luz del proyecto confesado posteriormente por "Sálvese quien pueda”. Un artículo de Catherine Den Tandt en particular se destaca por enfatizar la índole autodesconstructiva de "Letra para salsa y tres soneos por encargo", 
cuento que más de una vez se ha prestado a lecturas ingenuas que ven en él un “manifiesto feminista 'por excelencia”” (13). Si bien la protagonista, con una inesperada agresividad sexual, subyuga al machista que la piropea en la calle persistentemente, tal triunfo viene contaminado de otras formas de sujeción, esta vez encarnadas en la supuesta víctima femenina, cuyo desquite ha elegido una estrategia racista, clasista y, a fin de cuentas, confirmadora del machismo (13-9). La conclusión de la crítico es precisa: "Las múltiples e incluso conflictivas dimensiones de este relato se vuelven de definición casi imposible; para el lector 'Letra para salsa...' funciona como un campo minado de intenciones que se intersectan” (19). Otra pieza de Vírgenes y mártires, “Ahí viene Mamá Yona”, ha sido también caracterizada como profundamente indeterminada e irresoluble: Aníbal González, con acierto, ha hecho ver que la opresión — pronorteamericana — y la abundancia alimenticia - se juntan en la figura de la matriarca, que "transida de ambivalencia" es protagonista de un relato antimatriarcal situado en un libro que contiene directrices feministas (297). Obviamente, Vega ha llevado a sus últimos extremos la ambigüedad de la Mamá Grande garciamarquiana, un obvio emblema de la tierra, la cultura popular y lo corporal, opuestos a la impersonalidad de la modernidad —y por ello, heroína del cronista que se enfrenta a la historia oficial-; pero, no menos, emblema que nos remite a las viejas estructuras feudales de dominio y gobierno, cuya hora ha llegado aunque inútilmente hayan intentado adueñarse de las fórmulas abstractas de la cultura moderna para perpetuar sus arcaicos derechos. "Pollito Chicken", otro cuento de la colección, que relata la aventura sexual de una turista "niuyorrican" aspirante a WASP con un despreciado gigolo puertorriqueño, ha sido igualmente leído de maneras contrarias: si bien Captain-Hidalgo ve en el grito orgásmico de la protagonista — "VIVA PUELTO RICO LIBREEEEEEEEEEEEEEEE”(79) — una prometedora toma de conciencia de su identidad (306), Ezra Engling agudamente ha señalado que tal grito es más "una expresión de su desesperación que de liberación” ya que, de regreso a Nueva York, nada parece haber cambiado en sus actitudes (349).

Pasión de historia y otras historias de pasión perfecciona el lenguaje polisémico y, por tanto, difícilmente alegorizable descubierto en Vírgenes y mártires. La imposibilidad de lecturas absolutamente rectas o figuradas se enfatiza desde la selección misma del título, un quiasmo — como ya lo ha observado la crítica aunque sólo tomando en cuenta la primera narración de la serie (Imperiale 141). De hecho, el orbe quiásmico que se construye desde el paratexto titular podría extenderse a todo el libro y más aún entenderse como invitación a “cruzar" significados sin la llaneza que exige la allegoresis tradicional (Empson 128). Una afirmación como esta está sustentada por la costumbre de la autora de encabezar sus textos con otras señales similares; piénsese, por ejemplo, en los epígrafes de los cuentos de Vírgenes y mártires que hemos recordado: uno tomado de Albert Memmi, "Un homme à cheval sur deux cultures est rarement bien assis” ("Pollito Chicken”); otro de Rubén Blades, "La vida te da sorpresas, sorpresas te da la vida” ("Letra para salsa...”); y otro más de Francisco Matos Paoli, “Queremos y no queremos” (“Ahí viene Mama Yona”) —es decir, una paradoja, un quiasmo y una antítesis respectivamente, figuras que coinciden en subrayar inversiones o reversiones, con una consecuente sugerencia de indecibilidad o, en el mejor de los casos, de absoluta artificiosidad o precariedad de toda certidumbre obtenida a través de medios verbales. La paradoja, también, dominará la retórica de los epígrafes de Pasión 
de historia y otras historias de pasión: desde la que antecede a todos los textos compilados, "Verisimilitude is a question of style", de Raymond Chandler; pasando por la del cuento “Ajustes S.A.”, “Hate oppression; fear the oppressed”, de V.S. Naipaul; hasta llegar a la de la nouvelle con que se cierra el libro, "and for memory I had substituted inquiry” de George Lamming. Nótese de paso que "Sobre tumbas y héroes”, título de dicha nouvelle, constituye ya una inversión, sólo que intertextual, segundo término quiásmico si lo colocamos después del título de la novela de Ernesto Sábato a la que alude.

El abanico de significados de la frase Pasión de historia y otras historias de pasión es amplio. La bisemia de la palabra "historia", que nos enfrenta ya al dilema de "ciencia" y “arte”, "verdad” y “ficción”, res y verba, es el núcleo del quiasmo y éste, por ello, podría interpretarse como amplificación, si no como celebración, de tal indeterminación. "Pasión”, colocada junto a "historia”, a su vez, podría sugerir el encuentro de subjetividad y objetividad extremas, así como su carácter peligrosamente intercambiable. Que entre esas polaridades se debatan anécdotas sobre la tensión entre hombres y mujeres, sobre la reconstrucción del pasado nacional y sobre la naturaleza misma del oficio literario es una muestra explícita de que la identidad sexual, la concepción de lo nacional y los principios estéticos se ven en este libro como fenómenos proteicos, inarticulables en un discurso respaldado por certidumbres últimas. Ya que nos hemos propuesto verificar en la escritura de Vega las formas que adquiere su proyecto antialegórico, convendría que a continuación examináramos con detenimiento dicha inestabilidad: ella es precisamente, además del marco en que poco a poco surgirán los elementos alegóricos del libro, el mecanismo de inversión o reversión de toda prédica tradicional y pacata.

Comencemos por la expresión misma, en la que predominan las vacilaciones. Unas veces, serán francas y estridentes, como en el caso de los anglicismos, diseminados en casi todas las narraciones, incluso cuando el personaje no es un "niuyorrican” y esperamos un conocimiento más sólido de los límites de su léxico — “morón” (51 y 88), “frizarme”, “fóquin golpes” (69), “el matres” (71); otras veces, serán más sutiles, como las muy hábiles, casi espontáneas torpezas gramaticales u ortográficas de la mayoría de los narradores, de cariz violento, escandaloso, por aparecer en medio de un discurso generalmente correcto “mandó a pedir” (21), “de arriba a abajo” (85), "setentinueve, sesenticinco” (103). Además de las fuentes de oscilación apuntadas, ha de agregarse otra no menos importante: el cultivo de la distonía, especialmente con la superposición de lo populachero y lo hiperculto "menos mal que no fallé, porque podría haber dado en un blanco más estratégico antes de tiempo y ahí sí que me poncho pal carajo per sécula seculorum” (69).

Una situación semejante se crea gracias a la manipulación tropológica que no sólo nos llega a través del movimiento pendular previamente descrito, sino que nos empuja a un terreno de excesiva "agudeza de ingenio" en la que unos conceptos se suman a otros interminablemente hasta elaborar un verdadero laberinto discursivo en que a duras penas podemos precisar el punto de partida, la excusa inicial para la digresión. El asesinato "pasional” de una mujer, por ejemplo, da pie a la siguiente acumulación:

Por estar rezando no fue, epitafia el Club de Esposas Condominadas mientras Machistas Unidos Jamás Serán Jodidos recoge la consigna heroica del asesino que se entrega al día siguiente en el cuartel del Hato Rey: La piqué porque me la pegó, versión urbanamente 
prosaica del viejo Mía o de naiden. Por supuesto que ninguno se preguntó por qué fulano que salió pitando cuando las vio malas no tuvo que gastarse ni un chavo prieto en curitas. Y a nadie se le ocurrió impugnar el yo-no-meto-la-cuchara-en-plato-ajeno de los espectadores que no abrieron la puerta cuando Malén vino a pedir el último aguinaldo. Se la vi, como se dice en francés criollo. (11)

Como resultado, la lectura debe hacerse más lenta, concentrarse en la creciente obscuridad del lenguaje, tan desafiante y satisfactorio estéticamente como el misterio policial de la anécdota. El ingenio barroco de todos los narradores de Pasión de historia y otras historias de pasión reifica las palabras, las convierte en artefacto, lo que nos hace de una vez por todas perder fe en el hallazgo final en las páginas de este libro de una sabiduría grave, exenta de manipulaciones retóricas. El conceptismo de Vega, de hecho, menos que apuntar a una inteligencia admirable, explota la faceta ridícula de toda inflación intelectualista del lenguaje y del pensamiento: "me dejó en ménage à trois entre el cansancio y el sueño" (14); "sé que ustedes son viejas amigas [...], solidaridad clitoral a ultranza” (29); "íbamos para Hato Rey a poner pubis a la obra” (72); "le volvió a guiñar el ojo a la muchacha [...] quien lo recompensó esta vez con un despliegue pianístico de dientes” (106).

Inseguridades como las anteriores nos la ofrece a todo lo largo del libro la convivencia de la cultura de élite —alusiones a Rousseau (26 y ss.), al expresionismo alemán (32), a la mitología grecolatina $(46,53)$ — y la de masas — presencia de la telenovela (21), el cine de Hollywood (32, 81), de la Nueva Trova (127). La síntesis de esas disparidades es la descripción del apartamento de Danilo en "Caso omiso":

No vi nada para quitarle el sueño a uno. Ningún cadáver putrefacto, por ejemplo. Ni siquiera la posible arma homicida, llenita de huellas digitales y esperando ser descubierta por este Phillip Marlowe Junior. Sólo muebles estilo criollo antiguo de madera y pajilla, un tremendo piano de cola, carteles tipo Instituto de Cultura, muchos libros en las tablillas y una selva de matas de interior alrededor de una estatua blanca recostada como una emperatriz romana (pero sin uvas, ja, ja) sobre un pedestal de madera. El componente ultramoderno y el televisor desentonaban del resto de aquella sala middle-class boricua de ex-vanguardia. Don Danilo y doña Lucrecia eran obviamente personas cultas del tipo que va a Bellas Artes y ve Mirador Puertorriqueño [...] (77)

El espectáculo no puede dejar de recordarnos las acertadas descripciones del hibridismo cultural latinoamericano hechas por García-Canclini algunos años después, tomando en cuenta la configuración del hogar de las clases medias y altas:

[...] coexisten bibliotecas multilingües y artesanías indígenas, cablevisión y antenas parabólicas con mobiliario colonial, las revistas que informan cómo realizar mejor especulación financiera esta semana con ritos familiares y religiosos centenarios. Ser culto, e incluso ser culto moderno, implica no tanto vincularse con un repertorio de objetos y mensajes exclusivamente modernos, sino saber incorporar[los] a matrices tradicionales $[\ldots](71-2)$

¿Cómo evaluar un mundo así caracterizado? ¿Cuál ha de ser nuestra escala de valores y dónde situarla? ¿Hemos de adoptar la perspectiva del lector culto tradicional o la del 
acostumbrado a la banalidad del capitalismo tardío? La respuesta, sin embargo, no se halla en el texto.

Éste, por otra parte, nos remite tan frecuentemente fuera de sí que su autonomía fenoménica puede ponerse en duda. Más que una lectura, nos vemos obligados a practicar muchas lecturas simultáneas, porque el campo por el que nos desplazamos es el intertextual e incluso el transartístico. Una breve lista de las citas, paráfrasis u alusiones hechas en los distintos relatos de Pasión de historia... debería incluir nombres del ámbito literario, musical o cinematográfico como los de Daphne du Maurier, Truffaut, Poe, Cortázar, Ennio Morricone, Stephen King y muchos otros, de raleas tan diversas como lo permiten los tipos de culturas que constantemente se entrecruzan.

Más decisivas que todo lo anterior son las manipulaciones genológicas de la autora. Ya ha sido comentado el hecho de que lo detectivesco o policíaco, esencial en "Pasión de historia”, “Ajustes S.A.”, “Caso omiso” y "Sobre tumbas y héroes”, y que podría en principio entenderse como modulación genérica, es más bien una reversión de los cánones de la literatura negra, puesto que no se nos ofrece ni trivialidad ni detectives profesionales o demasiado diestros, y, por otra parte, el lector es quien se ve en la obligación de buscar la clave final de cada uno de los crímenes o enigmas (Galván 140). Pero hay más elementos que contribuyen a crear un espacio recargado de indeterminación. De todos los libros de Vega estamos probablemente ante el más heterogéneo desde el punto de vista del repertorio genérico. Si bien colecciones de sus ensayos como El tramo ancla (1988) y Esperando a Loló son igualmente híbridas, esa cualidad es de esperar en el género, célebremente apodado “centauro” por Alfonso Reyes. En el caso de Pasión de historia... la discontinuidad de los distintos subtipos narrativos que nos presenta resulta sorpresiva después de la homogeneidad de Vírgenes y mártires y Encancaranublado. Si en el libro de 1987 hay cuentos que se ajustan a las expectativas tradicionales en el siglo xx —en Hispanoamérica esas expectativas podrían sintetizarse en los paradigmas ofrecidos por la progresión teórica que va de Poe a Cortázar, pasando por Quiroga—, otros textos inmediatamente se perciben como anómalos, es decir, como pertenecientes a categorías distintas del cuento, imprecisión contenida ya en el término "historias". "Sobre tumbas y héroes” por su extensión en páginas y su complejidad argumental se asocia a narraciones supracuentísticas; los dos indicadores genéricos del subtítulo — indudablemente jocosos, aunque sólo en relación con la tramalo confirman: "Folletín de caballería boricua”. "Tres aeróbicos para el amor” y "Serie negra”, por su misma estructura de ciclos autónomos dentro del conjunto del libro, ya delatan un rango fenoménico peculiar, que se hará incluso más claro cuando nuestra lectura tropiece con procedimientos típicamente líricos semejantes a los que surgen en lo que Joyce Carol Oates ha denominado, en oposición al cuento, "miniature narratives" (193) o a lo que la crítica hispanoamericana ha venido conceptuando como "minicuento”, "microcuento” y otros marbetes semejantes. Esta especie de relato se caracteriza no sólo por su brevedad extremada, sino por otros rasgos entre los cuales se destaca una tensión verbal que determina y origina las tensiones de la anécdota. En otras palabras, solemos localizar en una frase o un vocablo lo que Michael Riffaterre, en su estudio del poema, llama "hipograma”, o sea, señal idiomática de una "matriz” de la totalidad textual (23). La narración se transforma, así pues, en la dramatización del asombro o la conmoción estética que nos producen giros de la lengua o elementos léxicos menores (Gomes 176-8). En “Tres aeróbicos para el amor” 
esa dependencia de hipograma y argumento se verifica en la reificación de los subtítulos dentro del mismo relato: "Una” trata de una mujer divorciada que se encuentra a sí misma en su soledad; "Dos" trata de un par de amantes que se da cuenta de lo afortunados que son de nunca haberse casado; y “Tres”, de un matrimonio feliz incluso sin tener hijos, pero cuya serenidad es asediada por la duda, patente en una jintanjáfora final que deja entrever la presencia de un vacío: “Contra viento y marea, truene o relampaguee, tal para cual más uno, casaditos los tres" (63). "Serie negra" explota estrategias poéticas de modo menos soterrado: los tres microcuentos que lo componen concluyen con una remisión a frases que han alcanzado la petrificación del cliché; sólo que tal remisión subvierte el lugar común y esa inversión, una vez amplificada, es lo que se pone en escena en todo el texto. "Delito sin cuerpo", que termina con la sentencia "noche tras noche la misma pesadilla compartida”, habla de una pareja que sueña rutinariamente que se apuñala el uno al otro (97); "Más acá”, cuya conclusión, “te dije que eras mía para siempre”, está en boca del que acaso es un fantasma, relata la fantasía masturbatoria de una viuda que pese a sus esfuerzos no puede escapar del recuerdo de su marido (98); "Salto vital”, monólogo de un suicida al que han salvado, acaba con la aparente resignación de “y aquí estoy otra vez. Será otro día”, que da pie tanto para suponer una aliviada reconciliación con la realidad como, inversamente, una continuación no conciliatoria, aunque sí hecha hábito, del deseo de destrucción personal (99). No cuesta entrever las consecuencias de que en un libro coincidan textos narrativos sobre problemas sociales o nacionales y textos que tienden abiertamente a lo lírico: la naturaleza discursiva, formal de estos contamina a aquellos de una literariedad —o sea, “ficcionalidad”, puesto que leer algo como literatura es leerlo como ficción (Culler 128)— que la aparente referencialidad podría hacer olvidar al lector inadvertido.

En lo que respecta al tratamiento de los personajes y su papel en la trama, la indeterminación general se fortalece, en primer lugar, por los juegos usuales de lo detectivesco, que depende de la duda acerca de la culpabilidad o la inocencia de quienes intervienen en las acciones — ejemplo perfecto, por sus cambios radicales de estatus, es el de Danilo en "Caso omiso"-; en segundo lugar, por el hecho de que la solución del misterio, como sucede en "Pasión de historia”, sólo podría ser ofrecida por el lector y éste carece de la autoridad literaria cuya fuente en nuestra cultura, al menos hasta ahora, ha sido y es el autor, o lo que de él imaginamos o sabemos (Foucault 101 y ss.). A esto puede sumarse que, imaginalmente, algunos personajes son la cifra de lo híbrido — la "Suprema Socia Benefactora” de “Ajustes S.A.” es en realidad un travesti, con todo lo que esto supone: un hombre que para defender una causa machista ha tenido que renunciar a ciertos demarcadores sociales de la "hombría" y ha tenido también, ya antes, en su faceta de "hombre normal", que erradicar de sí cualquiera de los defectos del machismo tradicional para perturbar y enloquecer a las feministas radicales. Éticamente, tampoco deja de ser problemática la valoración de algunos personajes, como el Virgilio de "Sobre tumbas y héroes”, en la vida presente, oráculo patriótico con el que simpatizamos, y ayer, no menos, delator.

Justamente en relación con los personajes y sus acciones, la indeterminación afectará de manera más evidente todo intento de lectura que se ciña a la costumbre de esperar “Grandes Metáforas”, es decir, alegorías. No pasemos por alto que una narración explícitamente vinculada a la historia patria, “Sobre tumbas y héroes”, está minada de 
ambivalencias. La de don Virgilio que he apuntado es sólo una; podríamos agregar otras que conviven con ella en esta misma nouvelle. El espacio propicio para la ambigüedad de inmediato salta a la vista en una alegoría nacional: el viejo espiritista que, tras verse en otra vida obligado a traicionar a los héroes de un movimiento independentista sueña con ellos y los echa de menos, recuerda al Puerto Rico que añora la independencia sin haberse sacrificado realmente por ella; recuerda incluso a los sectores no minoritarios que hoy se alimentan de discursos patrióticos pero, paradójicamente, en el pasado han impedido el advenimiento de una república emancipada al haberse cruzado de brazos ante el colonialismo o haberse opuesto a quienes han querido acabar con él sin recaer en las medias tintas. Tal lectura didáctica o cualquier otra que se haga, con todo, se desestabiliza gracias al desenlace. La crítica se ha mostrado particularmente perpleja ante él. O se ha contentado con él y por eso lo tilda de "convencional” y hasta de "escapista”, sea por la felicidad que rezuma, sea por la presencia de elementos “fantásticos” (Galván 142-3). Sin embargo, el hecho de que don Virgilio, conducido por el espíritu de “El Indio”, finalmente ascienda por una escalera de Jacob y se reúna con los patriotas muertos en el Más Allá y con su amor, Mercedes, precisamente puede entenderse como negación del facilismo alegórico que empapa al resto del relato. Y la razón está en el código kitsch cuyos “estilemas” o “vestigios”, como diría Eco (The Open Work 215 y 274), aquí irrumpen —ya antes anunciados, por ejemplo, por fotos de Libertad Lamarque que todo lo observan con "socarronería” (Pasión de historia 108 y 139-40). Libertad: curiosa convergencia en un nombre de lo más deseado y, a la vez, de lo cursi. En efecto, la intrusión de lo kitsch actúa como obstáculo que impide conocer los límites entre lo sublime y lo ridículo en lo que hemos leído. La exagerada elevación de la conclusión puede estar delatando la ironía con que la voz narrativa ha ido fabricando su alegoría de la nación como misterio por resolver — ¿dónde está la tumba de los patriotas? se preguntan los jóvenes investigadores amigos de Virgilio— - o la nación como campo de traiciones y arrepentimientos, desesperanza e ilusión.

La índole indescifrable de la modulación alegórica de este texto se hace más radical si nos detenemos a meditar en la onomástica: Emanuel, de orientación independentista, quien se esfuerza en dar con la "intra-historia" borrada por los discursos oficiales, de una u otra manera ilustra el mesianismo típico de la responsabilidad intelectual isleña, y, pese a la amistad, contrasta dramáticamente con el espiritista testigo del pasado:

[...] se lanza de pecho, exhibe sin pudor su pasión de historia [...], la épica oculta, la canción de gesta de los supuestamente derrotados. Aquí, intermedio respiratorio para que don Virgilio ejerza un derecho al aplauso que no ejerce. Viene entonces el tema obligado: la importancia revolucionaria de los líderes asesinados, su identidad netamente antillana [...]. Pero el viejo ni pío [...] (107)

Justamente, Virgilio se convierte en su contrario si pensamos en la duplicidad de su nombre: poeta de la épica nacional, ciertamente, pero guía de Dante en el infierno y el purgatorio, y a esos espacios confinado. En el ámbito quiásmico y movedizo de "Sobre tumbas y héroes”, no obstante, este Virgilio es también un Dante que se reencontrará con su Beatriz, llamada ahora Mercedes, en una experiencia conclusiva y paradisíaca.

Por si la dificultad de ser exactos en la comprensión del significado de esos nombres fuese poca — son alegoremas, es decir, unidades mínimas de alegorías o indicios de ellas; 
sin embargo, aquí parecen no ajustarse satisfactoriamente a un discurso mayor-, repárese en otros elementos similares dispersos en "Sobre tumbas y héroes”: ¿qué quiere decir la aparición de una "estrella" en el parabrisas de Emanuel, luego de que cae sobre su auto un "robusto fruto del trópico" y de que ha estado el conductor meditando con su acostumbrada rimbombancia comprometida? ¿Es la "bandera” que quiere todo el tiempo tener ante sus ojos y se le ha aparecido? ¿Hemos de reírnos? ¿Ha de interpretarse como premonición de que descubrirá el secreto de la tumba de los patriotas? ¿ O más bien presagia que la retórica de Emanuel o sus descubrimientos estarán afectados por los accidentes y las deformaciones, son un parabrisas —o una óptica— “rajados” (117)? Por otra parte, ¿cómo entender el no menos llamativo y provocador detalle, sin duda legible como algo más profundo, de que los restos de los patriotas muertos estén en un terreno ocupado hoy día por una "comuna gringa” de fanáticos religiosos?: “¿Las tumbas de dos héroes de Lares en garras de una partida de calvos de quién sabe qué secta satánica y bajo la dudosa jurisdicción de un tal Míster Klin?” (133). Si hacemos lecturas figuradas, dos contradictorias son admisibles en este contexto: o el discurso colonial oculta la verdad patriótica, o esta misma es suelo sobre el que lo delirante y lo fanático se ha instalado o puede sin problemas instalarse — no perdamos de vista la crítica de "Sálvese quien pueda".

A todo lo largo del libro se multiplican los problemas que enfrenta la allegoresis nacionalista o comprometida sin imaginación. En "Caso omiso", el nombre de la supuesta víctima de un machista asesino es Lucrecia, pero ya un personaje impone la necesaria distancia con respecto a la seriedad de las lecturas feministas alegorizantes: "Lucrecia (guféense el nombre)” (73). Las puertorriqueñas de "Pasión de historia”, asimismo, comen un plato nacional en “contra-conmemoración” de "la infausta fecha de la pseudo-constitución puertorriqueña”, pero ese ritual se efectúa en Francia en casa del mal marido francés de una de ellas, apoyado por su madre (23): si ya una interpretación feminista se topa con los contrasentidos que Aníbal González apuntaba en “Ahí viene Mama Yona” —el patriarcado y matriarcado cooperan en la violencia—, una nacionalista forzosamente vacilaría, por la descontextualización del opresor de lo puertorriqueño, en este caso ni estadounidense ni español.

La acumulación de alegoremas es tan abrumadora, pero tan imprecisa en el marco de oscilaciones y entrecruzamientos que hemos comentado, que en el plano de las interpretaciones ideológicas no se disimula demasiado la posibilidad de un choteo inteligente y sistemático, igual al del plano estilístico. No en balde ha asegurado Ana Lydia Vega en uno de sus ensayos, "Nosotros los historicidas":

[...] un rasgo esencial parece distinguir el furor historizante de nuestros escritores actuales del de sus predecesores literarios: y ese rasgo es quizá el de la ironía. Una aguda conciencia del ridículo, que viene del desinflamiento de las pretensiones mesiánicas, la desconfianza de los discursos enlatados y la aceptación de la relatividad de toda perspectiva, informa la nueva gestión narrativa. (Esperando a Loló 104) 
III. Últimos APUNTES

Aparte de la coexistencia de una obra narrativa y una teórica donde la práctica antialegórica se verifica, otro motivo por el que en este estudio he seleccionado a Vega entre varios escritores hispanoamericanos recientes que nos podrían servir de ejemplo es porque en ella la estética de lo “abierto”, lo constantemente susceptible de reinterpretación y, por tanto, desdeñoso de lecturas conformistas, alcanza sus mayores extremos. De hecho, la figura autorial que ofrece la ensayista viene también imbuida de ambigüedades:

["Yo no como flores", fue una de mis frases de infancia.] Cada vez que me invitan a comer [...] los parientes desentierran la polvorienta anécdota de los anales analidiescos para combatir mi vegetarianismo [...]. No ha sido fácil. De hecho, cualquier opción minoritaria es dura en el planeta. Y cuando se arrejuntan, ¡ni hablar! Imagínense el traumón de una mujer, negra, judía, homosexual, puertorriqueña, independentista, comunista, feminista y ¡VEGETARIANA! Que no es mi caso, por siaca... Pero admitan que seis de nueve no es mal promedio para empezar. (Tramo ancla 270)

Que un personaje así configurado elabore narraciones que se resisten a convertirse en dogma no es de extrañar.

Podría argüirse que la indeterminación de Vega puede alegorizarse también en términos nacionales: el mundo de esta ficción es inestable porque remite a una identidad colectiva hasta ahora indefinida. Con todo, costaría demasiado situar dicha sugerencia tanto en las disertaciones contra el mesianismo patriótico de la ensayista como en las sátiras de él que hace la narradora en Pasión de historia y otras historias de pasión. La movilidad de su visión de lo nacional no esconde, así, la "normalización” que Terry Eagleton ha visto como peligroso "autoritarismo" camuflado en el pensamiento de Iser y otros críticos interesados en textos abiertos (81).

He hablado de "antialegorías". No he empleado el prefijo "post” en parte porque éste tiene una función muy específica, como hemos visto, en el vocabulario de Carolynn Van Dyke y, en parte, porque empresas como las de Vega no prescinden terminantemente, no dejan atrás ni sepultan lo alegórico. Recurren a algunos de sus elementos y estrategias nombres culturalmente resonantes; creación de sucesos sospechosos, misteriosos; paralelismos al parecer significativos-, pero más bien para enfrentarlos con una imposibilidad de comprensión coherente y total. Es decir, son una crítica activa de un tipo de escritura y lectura tradicional; sin los referentes que constituyen estos últimos no tendría mayor sentido. La antialegoría convive conflictivamente con la alegoría del mismo modo que un texto "antipoético" no puede desgajarse de lo poético pese a sus burlas o que una “antinovela” existe contra aunque simultáneamente en función de la novela.

Creo oportuno concluir con una cita de Hans-Georg Gadamer que, a pesar de no referirse a una narrativa en primer lugar preocupada por las vicisitudes sociales, puede ayudarnos a vislumbrar cómo se produce el encuentro de lo alegórico y de su negación. "La interpretación”, ha dicho antes, “es parte de toda composición”. La alegoría es un artilugio literario que lo corrobora, pues supone que la obra está tomando en cuenta un horizonte de interpretación seguro y común para autores y público. Pero: 
[...] aun cuando haya [socialmente] una correspondencia estricta entre alegoría y significado, la totalidad del lenguaje poético en el cual se presenta este procedimiento todavía puede poseer la dimensión abierta de la indeterminación que le permita ser "poético", en el sentido de conceptualmente inagotable. Trataré de probarlo con un ejemplo. La discusión sobre los escritos de Kafka se ha centrado en la manera en cómo exitosamente construye un mundo cotidiano de un modo distante, lúcido, carente de pasión. Pero dicho mundo, aparentemente familiar, viene acompañado de un sentimiento misterioso de extrañeza que crea la impresión de que todas las cosas que le pertenecen nos remiten a otro orbe de significados. Sin embargo, no podemos interpretarlo todo como alegoría, precisamente porque el evento principal que las obras magistrales de Kafka nos presentan es la disolución de horizontes interpretativos comunes. La expectativa de que todo apunta a un significado o concepto descifrable se frustra. El texto evoca poéticamente el mero aspecto alegórico pero se abre a los dominios de lo ambiguo. (70-1)

Esos dominios, a mi entender, son los que explora actualmente lo mejor de la narrativa hispanoamericana que aún se siente atraída por la tarea de imaginar la nación.

\section{BibliografíA}

Ahmad, Aijaz. “Jameson's Rhetoric of Otherness and the 'National Allegory””. Social Text 17 (1987): 3-25.

Álvarez, Nicolás Emilio. "La metaficcionalidad de la historia y el discurso narrativo de 'El muerto’ de Borges”. Revista Iberoamericana 174 (1996): 137-48.

Benjamin, Walter. The Origin of German Tragic Drama. John Osborne, trad. George Stainer, intr. Londres: Verso, 1985.

Captain-Hidalgo, Yvonne. “El espíritu de la risa en el cuento de Ana Lydia Vega”. Revista Iberoamericana 162-3 (1993): 301-8.

Culler, Jonathan. Structuralist Poetics. [1975]. Ithaca: Cornell University Press, 1982.

Curtius, Ernst Robert. Literatura europea y Edad Media latina. Margit Frenk Alatorre y Antonio Alatorre, trad. 2 vols. México: Fondo de Cultura Económica, 1981.

de Man, Paul. Aesthetic Ideology. Andrzej Warminski, ed. Minneapolis: University of Minnesota Press, 1996.

Allegories of Reading. New Haven: Yale University Press, 1979.

Blindness and Insight. [1971]. Mineappolis: University of Minnesota Press, 1983.

Den Tandt, Catherine. “Tracing Nation and Gender: Ana Lydia Vega”. Revista de Estudios Hispánicos 1 (1994): 3-24.

Eagleton, Terry. Literary Theory. [1983]. Minneapolis: University of Minnesota Press, 1995.

Eco, Umberto. Semiotics and the Philosophy of Language. Blomington: Indiana University Press, 1984.

The Open Work. A. Cancogni, trad. Cambridge, MA: Harvard University Press, 1989.

Empson, William. Seven Types of Ambiguity. [1930]. Revised edition. Londres: Chatto and Windus, 1949.

Engling, Ezra. “Thematic and Narrative Strategies in Lydia Vega's [sic] 'Pollito Chicken'”. CLA Journal 3 (1996): 341-56. 
Fletcher, Angus. Allegory: The Theory of a Symbolic Mode [1964]. Ithaca: Cornell University Press, 1995.

Fowler, Alastair. Kinds of Literature. Cambridge, MA: Harvard University Press, 1982.

Foucault, Michel. The Foucault Reader. Paul Rabinow, ed. Nueva York: Pantheon Books, 1984.

Frye, Northrop. “Allegory”. Princeton Encyclopedia of Poetry and Poetics. Alex Preminger, ed. Princeton: Princeton University Press, 1974. Anatomy of Criticism. Princeton: Princeton University Press, 1957.

Gadamer, Hans-Georg. “Composition and Interpretation”. The Relevance of the Beautiful and Other Essays. R. Bernasconi, ed. N. Walker, trad. Cambridge: Cambridge University Press, 1996: 66-73.

Galván, Delia. “Sincretismo cultural en la estructura policíaca: Ana Lydia Vega y su Pasión de historia”. The Americas Review 3-4 (1993): 139-49.

García-Canclini, Néstor. Culturas híbridas. [1989]. México: Grijalbo, 1998.

Genette, Gérard. Paratexts. Jane Lewin, trad. Cambridge: Cambridge University Press, 1997.

Goethe, Johann Wolfgang Von. Maxims and Reflections. Elisabeth Shop. trad. Peter Hutchinson, ed. Londres: Penguin, 1998.

Gomes, Miguel. Los géneros literarios en Hispanoamérica: teoría e historia. Pamplona: Universidad de Navarra, 1999.

González, Aníbal. “Ana Lydia Vega: unidad y multiplicidad caribeñas en la obra de Ana Lydia Vega”. Revista Iberoamericana 162-3 (1993): 289-300.

Greenfield, Sayre. The Ends of Allegory. Newark: University of Delaware Press, 1998.

Hegel, George W. F. The Philosophy of Art. 4 vols. F. P. B. Osmaston, trad. Londres: G. Bell and Sons, Ltd., 1920.

Imperiale, Luigi. “Apalabrarse con su mundo: construcción palimpséstica sobre ‘Pasión de historia’ de Ana Lydia Vega”. Adelaida López Martínez, ed. Discurso femenino actual. Río Piedras: Editorial de la Universidad de Puerto Rico, 1995: 139-60.

Jameson, Fredric. “Third World literature in the era multinational capitalism”. Social Text 15 (1986): 65-88.

Lausberg, Heinrich. Elementos de retórica literaria. Mariano Marín Casero, trad. Madrid: Gredos, 1975.

Lewis, Clives Staples. The Allegory of Love: A Study in Medieval Tradition. Oxford: Clarendon Press, 1936.

Murphy, James. Rhetoric in the Middle Ages. Berkeley: University of California Press, 1981.

Oates, Joyce Carol. “Afterword”. The Assignation. Nueva York: Harper \& Row, 1989: 1935.

Quilligan, Maureen. The Language of Allegory: Defining the Genre. 1979. Ithaca: Cornell University Press, 1992.

Riffaterre, Michael. The Semiotics of Poetry. Bloomington: Indiana University Press, 1978.

Sommer, Doris. “Irresistible Romance: the Foundational Fictions of Latin America”. Homi Bhabha, ed. Nation and Narration. Londres/Nueva York: Routledge, 1995: 71-98.

Teskey, Gordon. Allegory and Violence. Ithaca: Cornell University Press, 1999. 
Van Dyke, Carolynn. The Fiction of Truth: Structures of Meaning in Narrative and Dramatic Allegory. Ithaca/Londres: Cornell University Press, 1985.

Vega, Ana Lydia, ed. Esperando a Loló y otros delirios generacionales. [1994]. Río Piedras: Editorial de la Universidad de Puerto Rico, 1996.

Pasión de historia y otras historias de pasión. [1987]. Buenos Aires: Ediciones de la Flor, 1994.

Encancaranublado y otros cuentos de naufragio. [1982]. Carolina, PR: Editorial Antillana, 1994.

Falsas crónicas del sur. [1991]. Río Piedras: Editorial Universidad de Puerto Rico, 1992.

El tramo ancla: ensayos puertorriqueños de hoy. [1988]. Río Piedras: EDUPR, 1989.

y Carmen Lugo Filippi. Vírgenes y mártires. [1981]. Río Piedras: Editorial Antillana, 1991. 